\title{
Evolution of stabilised creeping landslides
}

\author{
A. M. PUZRIN* and A. SCHMID*
}

\begin{abstract}
A simple analytical model is proposed to quantify evolution of a creeping landslide stabilised by a retaining wall, or by a natural barrier at the bottom of the sliding mass. Development in time of both the landslide displacements and the earth pressure acting on the retaining structure is obtained in the closed form, with the latter given by the classical Terzaghi expression for the average degree of consolidation. Depending on the value of the long-term safety factor, the landslide either eventually slows down, asymptotically approaching final displacements, or the soil behind the retaining wall comes to a passive failure, followed by a post-failure evolution of the landslide. The model is capable of quantifying both scenarios, with some of its features successfully validated against the monitoring and geotechnical data from the two case studies: the Combe Chopin and Ganter landslides in Switzerland. For the Combe Chopin landslide, which came to a standstill, the model has demonstrated its ability to predict final downhill displacements and their development in time. For the Ganter landslide, which failed and achieved steady-state velocity, the model correctly predicted the long-term landslide evolution and the effects of drainage and erosion on the displacement rates.
\end{abstract}

KEYWORDS: creep; landslides; soil stabilisation; case history
La présente communication propose un simple modèle analytique permettant de quantifier l'évolution d'une glissement de terrain progressif stabilisé par un mur de retenue, ou par la présence d'une barrière naturelle au bas de la masse glissante. On obtient, sous forme fermée, le développement en fonction du temps des déplacements du glissement de terrain et de la pression de la terre agissant sur la structure de retenue, cette dernière étant fournie par l'expression classique de Terzaghi pour le degré de consolidation moyen. En fonction de la valeur du facteur de sécurité à long terme, soit le glissement de terrain finit par ralentir, avec approche asymptotique des déplacements finaux, soit le sol situé derrière le mur de retenue atteint un point de rupture passive, suivi d'une évolution post-rupture du glissement de terrain. Le modèle est en mesure de quantifier les deux scénarios, avec validation de certaines de ses fonctions avec le contrôle et les données géotechniques des deux études de cas suivantes: les glissements de terrain de Combe Chopin et de Ganter, en Suisse. En ce qui concerne le glissement de terrain de Combe Chopin, qui s'est arrêté, le modèle a permis de démontrer sa capacité de prédire les déplacements finaux vers le bas, et son évolution progressive. Pour ce qui est du glissement de terrain de Ganter, avec rupture et développement d'une vitesse stable, le modèle a permis de prédire correctement l'évolution du glissement de terrain à long terme, ainsi que les effets du drainage et de l'érosion sur les vitesses de déplacement.

\section{INTRODUCTION}

Creeping landslides are a common feature in mountainous areas, and cause significant damage to buildings and infrastructure. The long-term stability of slowly moving landslides was a subject of early interest in soil mechanics (e.g. Terzaghi, 1936, 1950; Skempton, 1964; Skempton \& La Rochelle, 1965; Bjerrum, 1967). In these studies, the analysis focused mainly on progressive failure in overconsolidated clays, where the failure is delayed in time by the development of the negative excess pore water pressure caused by shearing. As soon as this excess pore water pressure dissipated, the landslides, which did not have any kinematic constraints, accelerated and failed.

Understanding of the failure mechanisms of creeping landslides continues to be of critical importance for assessment and mitigation of their hazard (Glastonbury \& Fell, 2008; Schulz et al., 2009). In general, when a creeping landslide is constrained by an obstacle - either natural (a rock outcrop) or artificial (a retaining wall) - it slows down, creating an impression of being stabilised (Bernander \& Olofsson, 1981; Wiberg et al., 1990; Puzrin \& Sterba, 2006). Sometimes, however, as in the case of the St. MoritzBrattas landslide in Switzerland, the stabilisation phase is succeeded by acceleration, which in this case was caused by

Manuscript received 29 April 2011; revised manuscript accepted 26 September 2011

Discussion on this paper closes on 1 November 2012; for further details see p. ii.

* Institute for Geotechnical Engineering, ETH Zurich, Switzerland. passive failure in the compression zone (Puzrin \& Schmid, 2011).

In order to explain the St. Moritz landslide phenomenon, Puzrin \& Schmid (2011) suggested a progressive failure mechanism based on the propagation of a shear band (where the shear strength drops to its residual value) into the compression zone along the slip surface of the landslide. This mechanism cannot, however, be applied to many landslides, which were stabilised after experiencing significant displacements along the entire slip surface, so that the shear strength had dropped to its residual value everywhere on the slip surface, before the landslide met the obstacle. The present paper is an attempt to suggest a mechanism covering this broader class of stabilised landslides.

Stabilisation of creeping landslides is normally attempted by constructing a drainage system in the landslide body. The efficiency of such a system depends on many factors, and in particular on how long such a system can remain open (i.e. not blocked by the fines) and intact (considering large inhomogeneous deformations in the sliding body). When the reliability of the drainage system is questionable, in smaller landslides it is often replaced by or combined with a retaining wall, protecting the infrastructure. Construction of the retaining wall creates an obstacle for the landslide, which initially slows down, in particular in its lower portion. If, however, the residual shear strength on the sliding surface is rate dependent, this apparent stabilisation can be accompanied by an increase of the earth pressures behind the retaining wall. If these pressures reach the passive earth pressure, the soil in the compression zone behind the wall 
may collapse, and the landslide will overflow the retaining structure. The landslide will then continue moving, eventually reaching a constant velocity again.

The purpose of this paper is to quantify this evolution of stabilised landslides by means of a simple analytical model, and to validate the model against the monitoring data from the Combe Chopin and Ganter landslides in Switzerland.

\section{THE MODEL}

\section{Assumptions}

The schematic layout of a landslide constrained by a retaining structure is shown in Fig. 1. The landslide state is characterised by displacements $\delta(x, t)$, velocities $\delta(x, t)$ and effective normal stresses $p(x, t)$, all parallel to the slope and averaged over the thickness of the sliding layer - that is, uniform with depth. Before being stabilised (stabilisation taking place at $t=0$ ), the landslide is assumed to have constant effective stress $p_{0}$ and be moving with constant velocity $v_{0}$, both values being uniformly distributed along the landslide length

$$
\begin{aligned}
& p(x, t)=p_{0}=\mathrm{const} \\
& \dot{\delta}(x, t)=v_{0}=\mathrm{const}
\end{aligned}
$$

both for $t<0$.

Provided the landslide has travelled sufficiently far before its stabilisation, the pressure at the lower and upper boundaries of the sliding layer and, as a consequence of assumptions (1), along the entire sliding layer, will become close to the active earth pressure, $p_{0} \approx p_{\mathrm{a}}$, and the residual strength $\tau^{*}$ will be fully mobilised along the entire sliding surface.

At the moment of landslide stabilisation $(t=0)$, the landslide displacements are taken as a reference (i.e. $\delta(x$, $0)=0$ ), and the retaining wall becomes the boundary of

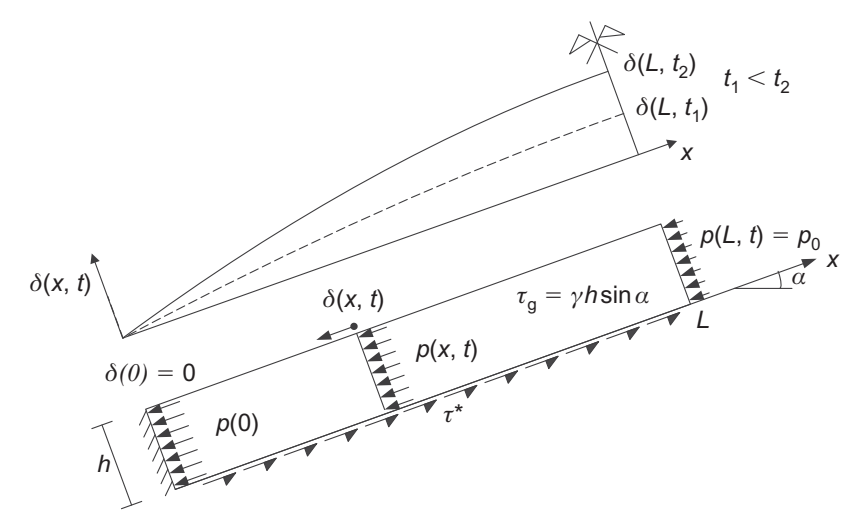

Fig. 1. Schematic layout of landslide constrained by retaining structure zero velocity for future landslide evolution $(t \geqslant 0)$ : $\dot{\delta}(0, t)=0$. The velocities in the sliding layer gradually begin to decrease, and the pressures to increase, with only the pressure at the upper boundary of the sliding layer remaining constant: $p(L, t)=p_{0}$.

This increase in pressures is due to the rate dependence of the residual strength on the sliding layer, which is assumed to exhibit rigid viscous-plastic behaviour (Fig. 2(a)),

$$
\tau^{*}=\tau_{\mathrm{r}}+\eta \frac{\partial \delta}{\partial t}=\tau_{\mathrm{r}}+\eta \dot{\delta}
$$

where $\tau^{*}$ is the residual shear strength of soil on the sliding surface, $\tau_{\mathrm{r}}$ is the rate-independent component of the residual shear strength, and $\eta$ is the viscosity coefficient. Soil behaviour in the sliding layer is assumed to be elasto-plastic (Fig. 2(b)), so that

$$
p=p_{0}+E \varepsilon=p_{0}+E \frac{\partial \delta}{\partial x}
$$

for $p<p_{\mathrm{p}}$, where $E$ is the deformation modulus of the soil, and $p_{\mathrm{p}}$ is the passive earth pressure.

\section{Differential equation} as

Equilibrium of the sliding layer (Fig. 3) can be expressed

$$
h \frac{\partial p}{\partial x}=\tau^{*}-\tau_{\mathrm{g}}
$$

where

$$
\tau_{\mathrm{g}}=\gamma h \sin \alpha
$$

is the gravitational shear stress.

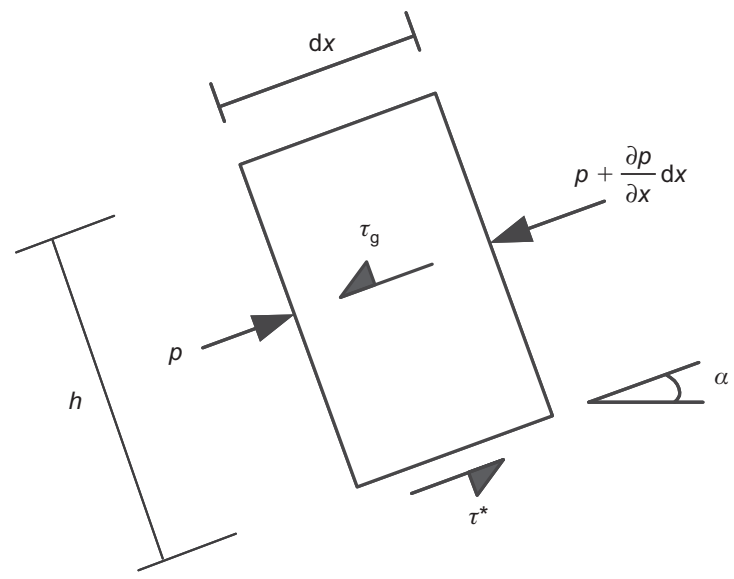

Fig. 3. Equilibrium of sliding layer

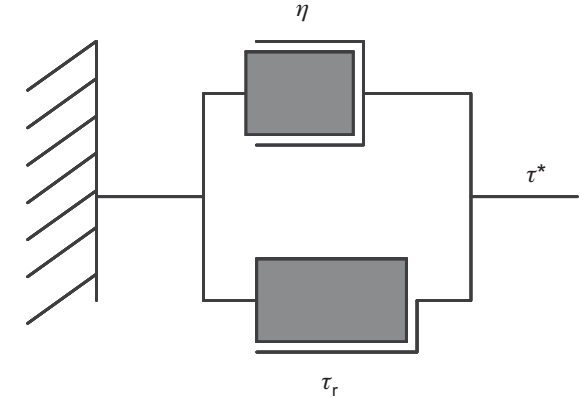

(a)

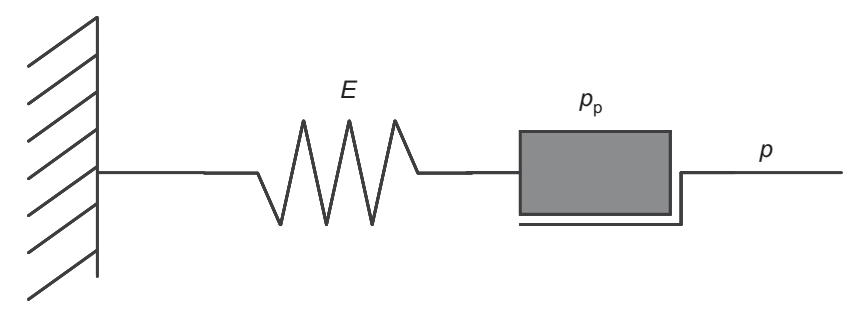

(b)

Fig. 2. Schematic constitutive behaviour of soil: (a) on the sliding surface; (b) in the sliding layer 
From equations (1) and (4) it follows that before the stabilisation the shear resistance is equal to the gravitational shear stress

$$
\tau^{*}(x, t)=\tau_{\mathrm{g}} \text { for } 0 \leqslant x \leqslant L, t<0
$$

and the velocity of the landslide follows from equations (1) and (2) as

$$
\dot{\delta}(x, t)=v_{0}=\frac{\tau_{\mathrm{g}}-\tau_{\mathrm{r}}}{\eta} \text { for } 0 \leqslant x \leqslant L, t<0
$$

After stabilisation, the differential equation for displacements is obtained by substitution of constitutive equations (2) and (3) into equilibrium equation (4) to give

$$
\frac{\partial \delta}{\partial t}=C \frac{\partial^{2} \delta}{\partial x^{2}}+v_{0}
$$

where

$$
\begin{aligned}
C & =\frac{h E}{\eta} \\
v_{0} & =\frac{\tau_{\mathrm{g}}-\tau_{\mathrm{r}}}{\eta}
\end{aligned}
$$

The boundary conditions are given by the zero displacement at the bottom and constant stress (and strain) at the top boundary of the landslide

$$
\begin{aligned}
& \delta(0, t)=0 \\
& \left.\frac{\partial \delta}{\partial x}\right|_{x=L}=0
\end{aligned}
$$

The initial conditions are given by the zero reference displacement at the moment of stabilisation

$$
\delta(x, 0)=0 \text { for } 0 \leqslant x \leqslant L
$$

which after substitution into the differential equation (8) takes the form

$$
\left.\frac{\partial \delta}{\partial t}\right|_{t=0}=v_{0} \text { for } 0 \leqslant x \leqslant L
$$

consistent with the second condition (equation (1a)) before the stabilisation.

\section{Solution}

Equation (8) can be recognised as a non-homogeneous heat equation, which in combination with the boundary conditions (equations (10)) produces a mixed boundary-value problem (BVP). It is more convenient, however, to transform it into the first BVP by fictitiously extending the landslide length to $2 L$ and imposing the boundary conditions

$$
\begin{aligned}
& \delta(0, t)=0 \\
& \delta(2 L, t)=0
\end{aligned}
$$

Note that in this case the original second boundary condition (equation 10b) is satisfied automatically, owing to the symmetry of the solution with respect to $x=L$.

The initial condition is being extended to the fictitious part,

$$
\delta(x, 0)=0 \text { for } 0 \leqslant x \leqslant 2 L
$$

The solution of the first BVP for the non-homogeneous heat equation (10) is given by

$$
\delta(x, t)=\int_{0}^{t} \int_{0}^{2 L} v_{0} G(x, \xi, t-T) \mathrm{d} \xi \mathrm{d} T
$$

where $\xi$ and $T$ are integration variables for space and time respectively, and

$$
G(x, \xi, t-T)=\frac{2}{2 L} \sum_{n=1}^{\infty} \sin \left(\frac{n \pi}{2 L} x\right) \sin \left(\frac{n \pi}{2 L} \xi\right) \mathrm{e}^{\frac{-C n^{2} \pi^{2}}{4 L^{2}}(t-T)}
$$

is the Green function for the first BVP.

Substitution of equation (16) into equation (15) with subsequent integration produces

$$
\begin{aligned}
\delta(x, t)= & \frac{v_{0}}{C L} \sum_{n=1}^{\infty}\left(\frac{2 L}{n \pi}\right)^{3} \sin \left(\frac{n \pi}{2 L} x\right)[1-\cos (n \pi)] \\
& \times\left(1-\mathrm{e}^{-\frac{C n^{2} \pi^{2}}{4 L^{2}} t}\right)
\end{aligned}
$$

It can be observed that all the even terms (for $n=2,4,6$, ...) in the sum in equation (17) vanish. Therefore the solution of the BVP can be presented as

$$
\begin{aligned}
\delta(x, t)= & \frac{2 v_{0}}{C L} \sum_{k=0}^{\infty}\left[\frac{2 L}{(2 k+1) \pi}\right]^{3} \sin \left[\frac{(2 k+1) \pi}{2 L} x\right] \\
& \times\left(1-\mathrm{e}^{-\frac{(2 k+1)^{2} \pi^{2}}{4 L^{2}} t}\right)
\end{aligned}
$$

It can be easily shown that equation (18) satisfies both the boundary (equations (10)) and initial (equation (11)) conditions.

For small $t$, displacements predicted by the solution in equation (18) can be approximated by the solution for the infinitely long slide $(L \rightarrow 0)$,

$$
\delta(x, t) \approx v_{0} \int_{0}^{t} \operatorname{erf} \frac{x}{\sqrt{4 C \xi}} \mathrm{d} \xi
$$

where

$$
\operatorname{erf}(x)=\frac{\sqrt{\pi}}{2} \int_{0}^{x} \mathrm{e}^{-x^{2}} \mathrm{~d} x
$$

is the error function.

For large $t$, displacements predicted by the solution in equation (18) can be approximated by

$$
\delta(x, t) \approx \frac{v_{0}}{C}\left[x L-\frac{x^{2}}{2}-\frac{16 L^{2}}{\pi^{3}} \sin \left(\frac{\pi}{2 L} x\right) \mathrm{e}^{-\frac{C \pi^{2}}{4 L^{2}} t}\right]
$$

with final displacements given by

$$
\begin{aligned}
\delta(x, \infty) & =\frac{v_{0}}{C}\left(x L-\frac{x^{2}}{2}\right) \\
& =\frac{\tau_{\mathrm{g}}-\tau_{\mathrm{r}}}{h E}\left(x L-\frac{x^{2}}{2}\right)
\end{aligned}
$$

\section{LANDSLIDE FAILURE AND POST-FAILURE EVOLUTION}

Pressures acting on retaining wall

For landslide stability analysis, the most important parameter is the pressure acting on the retaining wall, given by

$$
p=p_{0}+E \varepsilon(0, t)=p_{0}+\left.E \frac{\partial \delta}{\partial x}\right|_{x=0}
$$

Differentiation of equation (18) with respect to $x$ gives 
494

$$
\begin{aligned}
\varepsilon(0, t) & =\left.\frac{\partial \delta}{\partial x}\right|_{x=0} \\
& =\frac{v_{0} L}{C}\left[1-\frac{8}{\pi^{2}} \sum_{k=0}^{\infty} \frac{1}{(2 k+1)^{2}} \mathrm{e}^{-\frac{C(2 k+1)^{2} \pi^{2}}{4 L^{2}} t}\right]
\end{aligned}
$$

which is identical (!) to the Terzaghi solution for the average degree of consolidation (Terzaghi, 1943)

$$
\bar{U}\left(T_{\mathrm{v}}\right)=1-\sum_{k=0}^{\infty} \frac{2}{M^{2}} \mathrm{e}^{-M^{2} T_{\mathrm{v}}} \text { for } M=\frac{(2 k+1) \pi}{2}
$$

where $T_{\mathrm{v}}$ is the time factor, and variables in equations (23) and (24) are related by way of

$$
\begin{aligned}
& T_{\mathrm{v}}=\frac{C t}{L^{2}} \\
& \bar{U}\left(T_{\mathrm{v}}\right)=\frac{C \varepsilon(0, t)}{v_{0} L}
\end{aligned}
$$

This result is hardly surprising, however, because as for equation (8), Terzaghi's equation of one-dimensional consolidation is also a heat equation, although with two important differences: it is homogeneous, and $\bar{U}\left(T_{\mathrm{v}}\right)$ is obtained there by integrating the solution, rather than by differentiating as was done in equation (23).

The analogy with the Terzaghi solution indicates that its well-known approximations are also valid for equation (23), so that

$$
\text { for } \begin{aligned}
\bar{U} & =\left[C \varepsilon(0, t) / v_{0} L\right] \leqslant 0.526 \\
T_{\mathrm{v}} & =\frac{\pi}{4} \bar{U}^{2} \\
& \Rightarrow \varepsilon(0, t)=\frac{v_{0} L}{C} \sqrt{\frac{4 C t}{\pi} \frac{L^{2}}{C}}=\frac{v_{0}}{C} \sqrt{\frac{4 C}{\pi}} \sqrt{t}
\end{aligned}
$$

for $\bar{U}=\left[C \varepsilon(0, t) / v_{0} L\right]>0.526$

$$
\begin{aligned}
T_{\mathrm{v}} & =\frac{4}{\pi^{2}}\left[-\ln \frac{\pi^{2}}{8}-\ln (1-\bar{U})\right] \\
& \Rightarrow \varepsilon(0, t)=\frac{v_{0} L}{C}\left(1-\frac{8}{\pi^{2}} \mathrm{e}^{-\frac{C \pi^{2}}{4 L^{2}} t}\right)
\end{aligned}
$$

Substitution of equations (9), (26) and (27) into equation (22) produces approximate equations of the evolution of the earth pressure acting on the retaining structure.

For $t \leqslant 0 \cdot 217\left(L^{2} \eta / E h\right)$ :

$$
p(0, t)=p_{0}+\frac{\tau_{\mathrm{g}}-\tau_{\mathrm{r}}}{h} L \sqrt{\frac{4 h E}{\pi \eta}} \sqrt{t}
$$

For $t>0 \cdot 217\left(L^{2} \eta / E h\right)$ :

$$
p(0, t)=p_{0}+\frac{\tau_{\mathrm{g}}-\tau_{\mathrm{r}}}{h} L\left(1-\frac{8}{\pi^{2}} \mathrm{e}^{-\frac{h E \pi^{2}}{4 \eta L^{2}} t}\right)
$$

\section{Safety factor and time of failure}

The safety factor for the landslide long-term stability is defined, using equation (29), as

$$
\mathrm{FS}=\frac{p_{\mathrm{p}}}{p(0, \infty)}=\frac{p_{\mathrm{p}}}{p_{0}+\frac{\tau_{\mathrm{g}}-\tau_{\mathrm{r}}}{h} L}
$$

If this safety factor is larger than unity, the landslide will continue to slow down, asymptotically approaching its final displacements (equation (21)). If, however, FS $<1$, the earth pressure will eventually reach the passive pressure, and the soil behind the wall will fail. The time of failure $t_{\mathrm{f}}$ can be determined from equations (28) and (29) as follows.

For $t_{\mathrm{f}} \leqslant 0 \cdot 217\left(L^{2} \eta / E h\right)$

$$
t_{\mathrm{f}}=\frac{\pi \eta}{4 h E}\left(\frac{p_{\mathrm{p}}-p_{0}}{\tau_{\mathrm{g}}-\tau_{\mathrm{r}}} \frac{h}{L}\right)^{2}
$$

For $t_{\mathrm{f}}>0 \cdot 217\left(L^{2} \eta / E h\right)$

$$
t_{\mathrm{f}}=\frac{4 \eta L^{2}}{h E \pi^{2}} \ln \left\{\frac{\pi^{2}}{8}\left[\frac{h\left(p_{\mathrm{p}}-p_{0}\right)}{L\left(\tau_{\mathrm{g}}-\tau_{\mathrm{r}}\right)}-1\right]\right\}
$$

\section{Post-failure evolution}

Once the effective passive pressure $p_{\mathrm{p}}$ is reached at the bottom of the landslide, it stays constant, and the pattern of the landslide displacement changes. It is still governed by the same differential equation (8), but the boundary conditions are now given by the constant stress (and strain), both at the bottom and the top boundaries of the landslide

$$
\begin{aligned}
& \varepsilon(0, t)=\left.\frac{\partial \delta}{\partial x}\right|_{x=0}=\frac{p_{\mathrm{p}}-p_{0}}{E} \\
& \varepsilon(L, t)=\left.\frac{\partial \delta}{\partial x}\right|_{x=L}=0
\end{aligned}
$$

representing a non-homogeneous second (Neumann) BVP. The initial condition for this problem is obtained (for large $t_{\mathrm{f}}$ ) from equation (20), defining landslide displacements at the time of failure

$$
\delta(x, 0)=\frac{v_{0}}{C}\left[x L-\frac{x^{2}}{2}-\frac{16 L^{2}}{\pi^{3}} \sin \left(\frac{\pi}{2 L} x\right) \mathrm{e}^{-\frac{C \pi^{2}}{4 L^{2}} t_{\mathrm{f}}}\right]
$$

In this BVP, both the differential equation (8) and boundary conditions (equations (33)) are non-homogeneous. The solution for such a problem can be obtained as a superposition of two solutions of two simplified BVPs

$$
\delta(x, t)=\delta_{\mathrm{p}}(x, t)+\delta_{\mathrm{g}}(x, t)
$$

where $\delta_{\mathrm{p}}(x, t)$ is a particular solution of a homogeneous differential equation

$$
\frac{\partial \delta}{\partial t}=C \frac{\partial^{2} \delta}{\partial x^{2}}
$$

with non-homogeneous boundary conditions (equations (33)); $\delta_{\mathrm{g}}(x, t)$ is the general solution of the non-homogeneous equation (8), with homogeneous boundary conditions

$$
\begin{aligned}
& \varepsilon(0, t)=\left.\frac{\partial \delta_{\mathrm{g}}}{\partial x}\right|_{x=0}=0 \\
& \varepsilon(L, t)=\left.\frac{\partial \delta_{\mathrm{g}}}{\partial x}\right|_{x=L}=0
\end{aligned}
$$

and initial condition

$$
\delta_{\mathrm{g}}(x, 0)=\frac{v_{0}}{C}\left[x L-\frac{x^{2}}{2}-\frac{16 L^{2}}{\pi^{3}} \sin \left(\frac{\pi}{2 L} x\right) \mathrm{e}^{-\frac{C \pi^{2}}{4 L^{2}} t_{\mathrm{f}}}\right]-\delta_{\mathrm{p}}(x, 0)
$$

representing a homogeneous second (Neumann) BVP.

A particular solution satisfying both the differential equation (36) and non-homogeneous boundary conditions (equations (33)) is given by

$$
\delta_{\mathrm{p}}(x, t)=\frac{p_{0}-p_{\mathrm{p}}}{2 E L}\left(x^{2}-2 L x+2 C t\right)
$$


The general solution of the second BVP with nonhomogeneous equation (8), homogeneous boundary conditions (equations (37)) and initial condition (equation (38)) is given by

$$
\delta_{\mathrm{g}}(x, t)=\int_{0}^{L} f(\xi) G(x, \xi, t) \mathrm{d} \xi+\int_{0}^{t} \int_{0}^{L} v_{0} G(x, \xi, t-T) \mathrm{d} \xi \mathrm{d} T
$$

where

$$
\begin{aligned}
f(\xi)= & \delta_{\mathrm{g}}(\xi, 0) \\
= & \frac{v_{0}}{C}\left[\xi L-\frac{\xi^{2}}{2}-\frac{16 L^{2}}{\pi^{3}} \sin \left(\frac{\pi \xi}{2 L}\right) \mathrm{e}^{-\frac{C \pi^{2}}{4 L^{2}} t_{\mathrm{f}}}\right] \\
& -\frac{p_{0}-p_{\mathrm{p}}}{2 E L}\left(\xi^{2}-2 L \xi\right)
\end{aligned}
$$

is the initial condition given by equations (38) and (39), and

$$
G(x, \xi, t)=\frac{1}{L}+\frac{2}{L} \sum_{n=1}^{\infty} \cos \left(\frac{n \pi}{2 L} x\right) \cos \left(\frac{n \pi}{2 L} \xi\right) \mathrm{e}^{-\frac{C n^{2} \pi^{2}}{4 L^{2}} t}
$$

is the Green function for a homogeneous second BVP.

Substitution of equations (41) and (42) into equation (40), with subsequent integration and substitution of the result into equation (35) together with the particular solution in equation (39), produces a closed-form solution for the landslide displacements, which is rather bulky and will not be shown here, owing to lack of space. It is, however, rather straightforward to demonstrate that for $t \rightarrow \infty$ the time derivative of the first integral in equation (40) approaches zero, while the time derivative of the second integral in equation (40) approaches $v_{0}$. Therefore velocities of all the points along the landslide are asymptotically approaching a constant value

$$
\begin{array}{r}
\dot{\delta}(x, \infty)=\dot{\delta}_{\mathrm{p}}(x, \infty)+\dot{\delta}_{\mathrm{g}}(x, \infty) \\
=-C \frac{p_{\mathrm{p}}-p_{0}}{E L}+v_{0}
\end{array}
$$

which after substitution of equations (9) into it can be expressed by way of soil parameters as

$$
\dot{\delta}(x, \infty)=\frac{1}{\eta}\left[\tau_{\mathrm{g}}-\tau_{\mathrm{r}}-\frac{h}{L}\left(p_{\mathrm{p}}-p_{0}\right)\right]
$$

Note that for $p_{\mathrm{p}}>p_{0}$ this velocity will be smaller than the initial landslide velocity $v_{0}$ from equation (9), indicating that although the landslide movements could not have been eliminated completely, a certain degree of landslide stabilisation will be achieved, in spite of the passive failure of soil behind the retaining structure.

\section{SUMMARY}

Evolution of a creeping landslide, moving downhill with a constant initial velocity and earth pressure, and encountering a rigid obstacle at its bottom, has been considered. Displacements of such a landslide are given by equation (18), which can be approximated by equations (19) and (20), immediately and a long time after the stabilisation has taken place respectively.

This movement will, however, be accompanied by an increase of the earth pressure acting on the retaining structure, given by equations (28) and (29) for early and late stages of earth pressure evolution respectively. Depending on the value of the long-term safety factor (equation (30)), the landslide will either eventually slow down, asymptotically approaching final displacements (equation (21)), or the soil behind the retaining wall will experience passive failure at the moment in time given by equations (31) and (32).

After this passive failure takes place, the landslide displacements can be described using equations (35) and (39)(42). The landslide will then asymptotically approach a constant velocity (equation (44)), which will be lower than the initial velocity (equation (9)).

In the following, two case studies of landslides in Switzerland will be addressed in order to partially validate the proposed model.

\section{CASE STUDY: COMBE CHOPIN LANDSLIDE, SWITZERLAND \\ Description}

The A16 highway from Bern to Delémont and Basle is a major north-south link in Switzerland, and connects the capital city Bern to France (Fig. 4(a)). The highway crosses the creeping landslide of Combe Chopin (Fig. 4(b)), which is bounded by two hills located to the north and south of the landslide, respectively. This landslide is inclined from east to west with an inclination of $25-30^{\circ}$ (Bapst, 2002) towards the river Birse, which passes at the bottom of the landslide. The width of the two-part slide is about $150-200 \mathrm{~m}$, its length in general is about $140-190 \mathrm{~m}$. The northern part of the active portion is about $90 \mathrm{~m}$ long and $60 \mathrm{~m}$ wide (Fig. 5(a)). The soil of the landslide is composed of slope debris, a mixture of clay and gravel on top of a sliding surface of a thickness of $0.5-1.0 \mathrm{~m}$, which is also a mixture of clay and

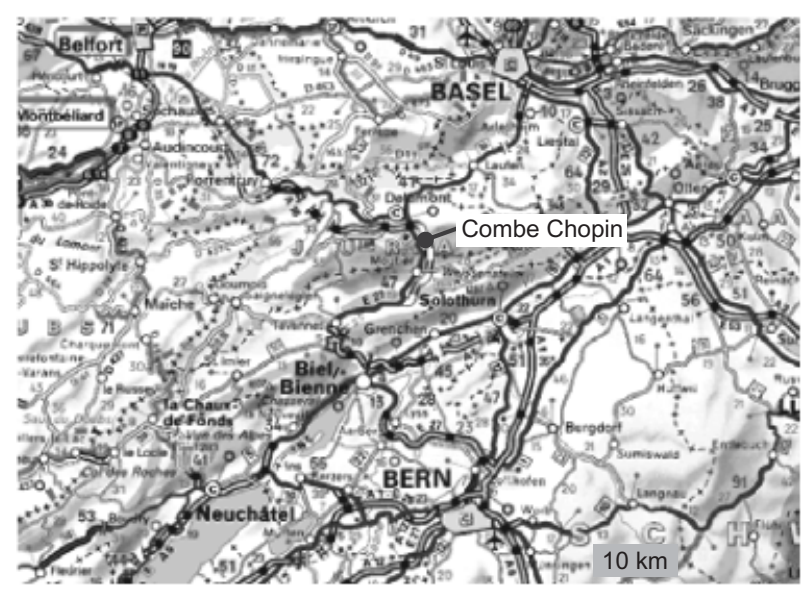

(a)

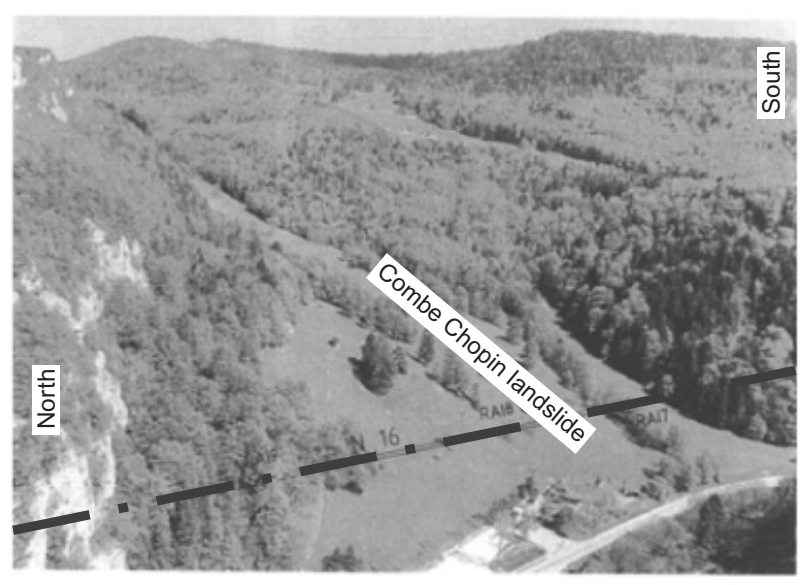

(b)

Fig. 4. Combe Chopin landslide: (a) location (Viamichelin, 2007); (b) view (after Bapst, 2002) 


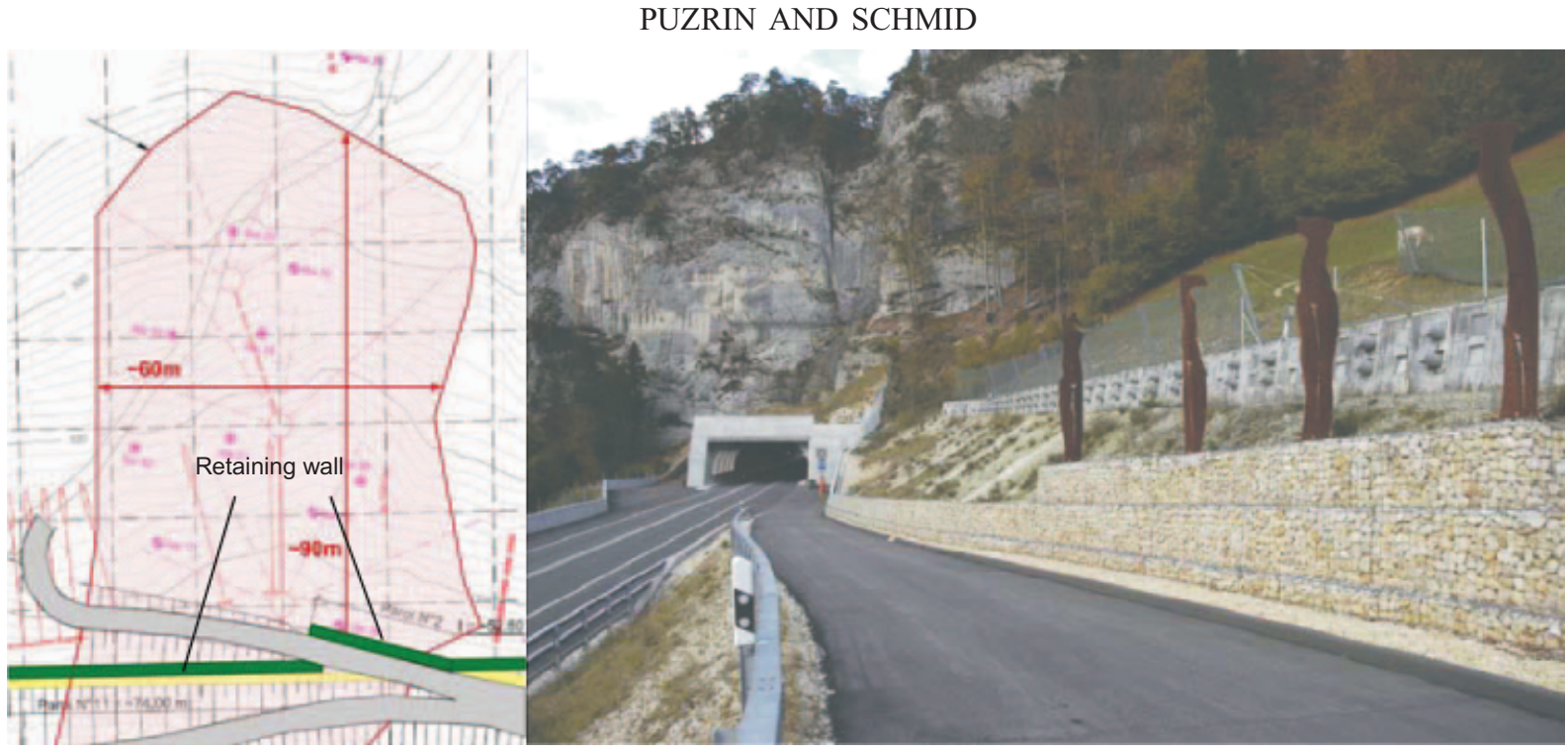

(a)

(b)

Fig. 5. Northern part of Combe Chopin landslide: (a) schematic outline of landslide; (b) photograph of wall (courtesy of Stump)

gravel. Below the sliding surface there is a zone of weathered rock with a thickness of $2-4 \mathrm{~m}$, followed by the solid rock. The landslide can be divided into a northern zone, with a landslide thickness of approximately 5-7 m, and a southern zone, with a landslide thickness of up to $14 \mathrm{~m}$. The hydrology is dominated by the less permeable layer of clay and gravel mixture.

The soil properties were defined in the laboratory tests: the effective peak strength parameters $\phi_{\text {peak }}^{\prime}=20 \pm 1^{\circ}$ and $c_{\text {peak }}^{\prime}=40 \pm 15 \mathrm{kPa}$ (direct shear); the residual angle of internal friction $\phi_{\text {res }}^{\prime}=18 \pm 3^{\circ}$ (ring shear); Young's modulus in compression $E=30 \pm 10 \mathrm{MPa}$ (consolidometer); and total unit weight $\gamma=20 \mathrm{kN} / \mathrm{m}^{3}$.

Creep deformations in the landslide had been observed and monitored since 1976, when the highway project started (Bapst, 2002). During the first stages of excavation in September 2000, displacements in the northern zone of the landslide (Fig. 5(a)) accelerated to $v_{0}=4 \pm 2 \mathrm{~mm} /$ day, with clearly observed tension cracks at the upper boundary of the slide (Bisetti, 2002). During the first half of 2001 the landslide was partially stabilised by installing a drainage system, which brought the groundwater level below the sliding surface. In the first half of 2002 an anchored, boredpile retaining wall was constructed (Fig. 5(b)), monitored using a TRIVEC measurement system, described in detail by Puzrin \& Schmid (2007), where also an early attempt was made to study the landslide mechanism. High anchor forces acting on the retaining wall resulted in the wall moving uphill for the $3 \frac{1}{2}$ years after tensioning of the anchors, until December 2005 , so that the zero displacement boundary was not at the wall, but in the landslide about $12 \mathrm{~m}$ above the wall. In addition to the TRIVEC measurements, downhill displacements of three points on the landslide (at distances of $13 \mathrm{~m}, 40 \mathrm{~m}$ and $63 \mathrm{~m}$ away from the zero displacement boundary) have been measured geodetically (Fig. 6).

\section{Analysis}

As can be seen in Fig. 6, the first geodetic measurement was taken 114 days after completion of the wall, and after 1119 days the slide came practically to a halt. The safety factor for the landslide is given by equation (30). Displacements of the landslide can be approximated by equations (19) and (20), immediately and a long time after the

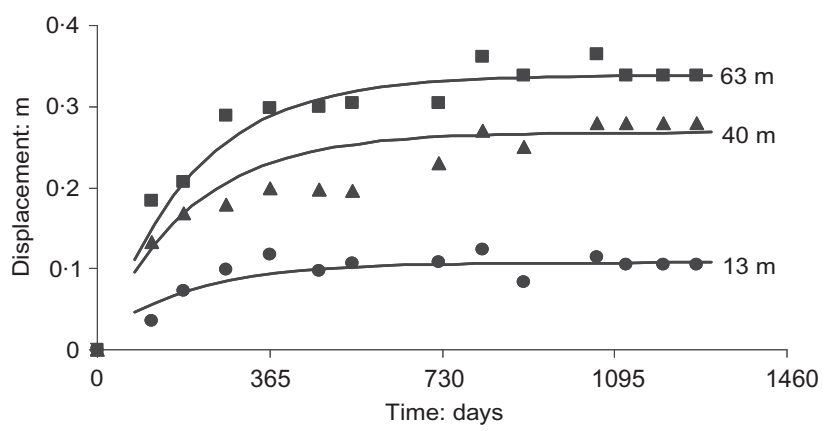

Fig. 6. Downhill displacements of three points in northern part of Combe Chopin landslide measured after construction of wall

construction of the retaining wall respectively. The final landslide displacements are given by equation (21). Evaluation of these expressions against the measured and monitoring data (summarised in Table 1) is given below.

First, the slide came to a halt and, as indicated by TRIVEC and anchor load cell measurements, the earth pressure on the retaining wall has also ceased to grow, apparently not reaching the passive earth pressure and indicating that the safety factor (equation (30)) is larger than unity. This conclusion can be verified, using equation (30) and Table 1, to estimate the passive pressure and compare its value with that determined independently from the peak strength estimates of the soil in the sliding layer. From equation (30) it follows that

$$
p_{\mathrm{p}}-p_{0} \geqslant \frac{\tau_{\mathrm{g}}-\tau_{\mathrm{r}}}{h} L=271 \mathrm{kPa}
$$

where $\tau_{\mathrm{g}}=\gamma h \sin \alpha=55.4 \mathrm{kPa}$ is the gravitational shear stress, and

$$
\tau_{\mathrm{r}}=\gamma h \cos \alpha \tan \phi_{\mathrm{res}}^{\prime}=34.6 \mathrm{kPa}
$$

is the residual shear strength in the absence of the groundwater table.

Evidence of the tension cracks before the slide stabilisation allows the initial pressure in the sliding body to be assumed to be close to the active earth pressure $p_{\mathrm{a}}$. The effective peak strength parameters consistent with the backcalculated pressure difference (equation (45)) are 
Table 1. Summary of physical and geometrical parameters for Combe Chopin landslide

\begin{tabular}{l|c|c}
\hline Parameter & Value & Derivation \\
\hline Landslide length, $L: \mathrm{m}$ & 78 & Measured (field) \\
Average depth of sliding surface, $h: \mathrm{m}$ & 6 & Measured (field) \\
Average depth of phreatic surface, $h_{\mathrm{w}}: \mathrm{m}$ & 6 & Measured (field) \\
Average slope inclination, $\alpha:$ degrees & $27 \cdot 5$ & Measured (field) \\
Total unit weight of soil, $\gamma: \mathrm{kN} / \mathrm{m}^{3}$ & $20 \pm 1$ & Measured (laboratory) \\
Peak angle of internal friction in sliding layer, $\phi_{\text {peak }}^{\prime}:$ degrees & $40 \pm 15$ & Measured (laboratory) \\
Peak cohesion in sliding layer, $c_{\text {peak }}^{\prime}: \mathrm{kPa}$ & 18 & Measured (laboratory) \\
Average residual angle of internal friction on slip surface, $\phi_{\text {res }}^{\prime}:$ degrees & 30 & Measured (laboratory) \\
Average Young's modulus: $\mathrm{MPa}$ & $55 \cdot 4$ & Calculated \\
Gravitational shear stress, $\tau_{\mathrm{g}}: \mathrm{kPa}$ & $34 \cdot 6$ & Calculated \\
Residual shear strength, $\tau_{\mathrm{r}}: \mathrm{kPa}$ & &
\end{tabular}

$\phi_{\text {peak }}^{\prime} \geqslant 20^{\circ}$ and $c_{\text {peak }}^{\prime} \geqslant 42 \mathrm{kPa}$, which broadly overlap with the measured ranges of $\phi_{\text {peak }}^{\prime}=20 \pm 1^{\circ}$ and $c_{\text {peak }}^{\prime}=40 \pm$ $15 \mathrm{kPa}$, confirming that the safety factor could indeed be FS $>1$.

Second, fitting equation (21) to the final displacement measured at 1269 days after wall construction (Fig. 7) produces a value of the parameter

$$
\frac{v_{0} L^{2}}{C}=0 \cdot 70
$$

where $L=90 \mathrm{~m}-12 \mathrm{~m}=78 \mathrm{~m}$ is the effective length of the landslide above the zero-displacement boundary. This parameter, however, can also be calculated independently, using equations (9) and average values for physical and geometric parameters of the problem summarised in Table 1, as

$$
\frac{v_{0}}{C} L^{2}=\frac{\tau_{\mathrm{g}}-\tau_{\mathrm{r}}}{h E} L^{2}=0.704
$$

indicating remarkable agreement between the fitted and directly calculated values.

Third, the best fit of the evolution of the landslide displacements in time (Fig. 6), for $x$ of $13 \mathrm{~m}, 40 \mathrm{~m}$ and $63 \mathrm{~m}$, is obtained by using equation (20) after substituting into it parameters $v_{0} L^{2} / C=0 \cdot 7, L=78 \mathrm{~m}$ and adjusting the initial velocity to

$$
v_{0}=1.5 \mathrm{~mm} / \text { day }
$$

This value is slightly below the lower bound of the range of $v_{0}=4 \pm 2 \mathrm{~mm} /$ day recorded during the landslide acceleration, correctly reflecting the effects of the drainage system constructed with the aim of slowing the landslide down. Velocity (equation (49)), when substituted together with equation (46) and $\tau_{\mathrm{g}}=\gamma h \sin \alpha=55.4 \mathrm{kPa}$ into equation (7), allows for the assessment of the viscosity $\eta=\left(\tau_{\mathrm{g}}-\tau_{\mathrm{r}}\right) /$ $v_{0}=1.20 \times 10^{9} \mathrm{kPas} / \mathrm{m}$, which is of the same order of

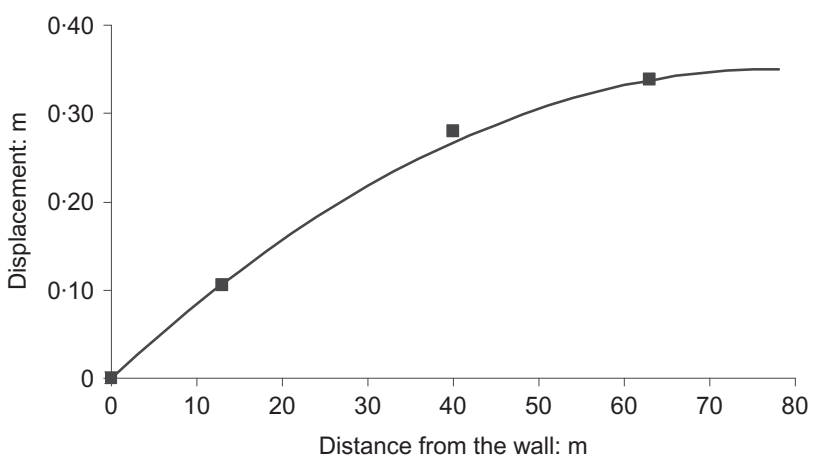

Fig. 7. Final downhill displacements along Combe Chopin landslide measured 1269 days after construction of wall magnitude as the viscosities back-calculated by van Asch et al. (2007) for two landslides in the French Alps.

It has to be verified, however, whether it is justified to use equation (20) for simulating the landslide displacements in Fig. 6, because this equation is suitable only for approximating the later stages of the landslide evolution. Following the Terzaghi solution analogy, the approximation becomes valid for

$$
t C / L^{2} \geqslant 0 \cdot 217
$$

Substitution of the back-calculated parameters from equations (47) and (49) into equation (50) provides the following range of the validity of equation (20): $t \geqslant 102$ days after completion of the wall. This justifies the application of this equation to simulating data in Fig. 6, where the first reading shown was taken $t=114$ days after completion of the wall.

\section{CASE STUDY: GANTER LANDSLIDE, SWITZERLAND Description}

The A9 highway via the Simplon Pass is one of the main connections between Switzerland and Italy through the Swiss Alps (Fig. 8(a)). Its most spectacular structure is the bridge over the Ganter river valley, built in 1980 (Fig. 8(b)). On the left bank of the river, the piers of this bridge are built on a creeping landslide, with the initial intention that the caissons cut through the sliding layer so that the pier foundations could be based in the stable rock. This landslide has an average inclination of around $24^{\circ}$ from south-east to northwest towards the Ganter river, which passes at the bottom of the landslide. The river bed deposits are squeezed between the landslide and the rock outcrop at the opposite river bank, representing a natural obstacle for the landslide: that is, no retaining wall is necessary.

The landslide is $1060 \mathrm{~m}$ wide and between $300 \mathrm{~m}$ and $500 \mathrm{~m}$ long. In the cross-section close to the Ganter bridge foundations, where the majority of the measurements have been taken, the length of the landslide is $440 \mathrm{~m}$. The soil profile of the landslide is built of slope debris, which is a mixture of gravel and stones within a sand and silt matrix, covering a bed of moraine (Lang \& Schaerer, 1973). The thickness of the sliding granular material is between $20 \mathrm{~m}$ and $22 \mathrm{~m}$ at the boundaries of the landslide, and $42 \mathrm{~m}$ in its middle section (Lang \& Schaerer, 1973). In the upper part of the landslide the granular material is based on the altered mica schist, in the lower part on the altered schist.

A preliminary geodetic field campaign was carried out between 1966 and 1974 (Schaerer, 1975). Starting from 1975, points 8, 9, 10, 11 and 12 have been measured in the area of the designed bridge (Figs 9(a) and 9(b)). A drainage system, combining horizontal drains at the bridge piers with the surface drainage of the streams and rainwater, was built in 1979-1982 to slow down the displacement rates, and 


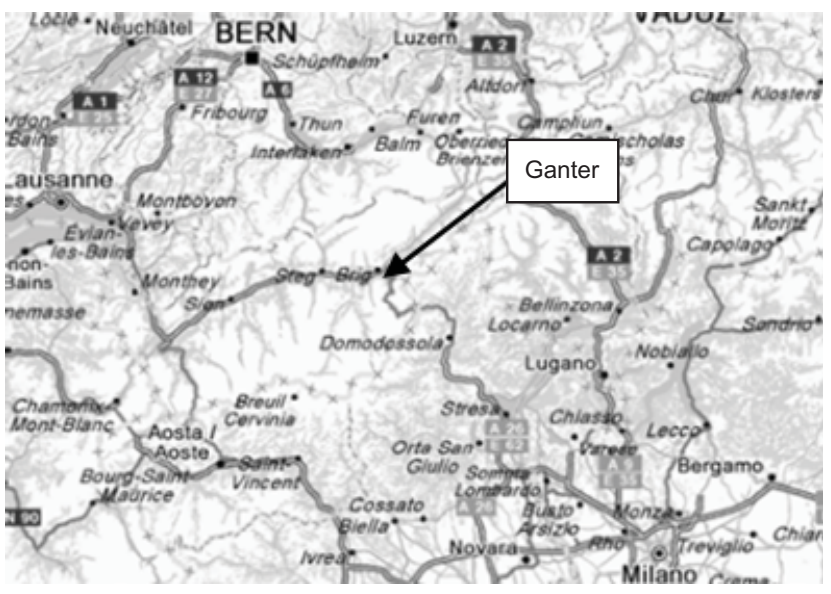

(a)

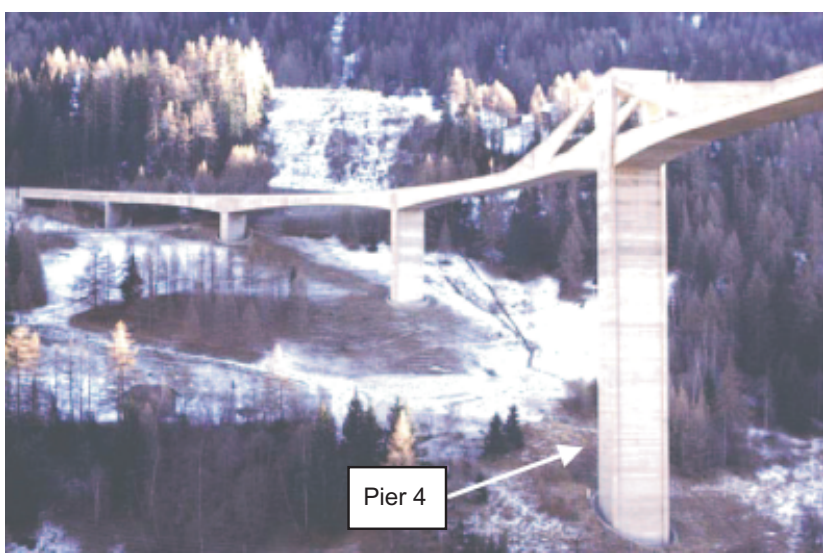

(b)

Fig. 8. Ganter landslide: (a) location (Viamichelin, 2011); (b) view
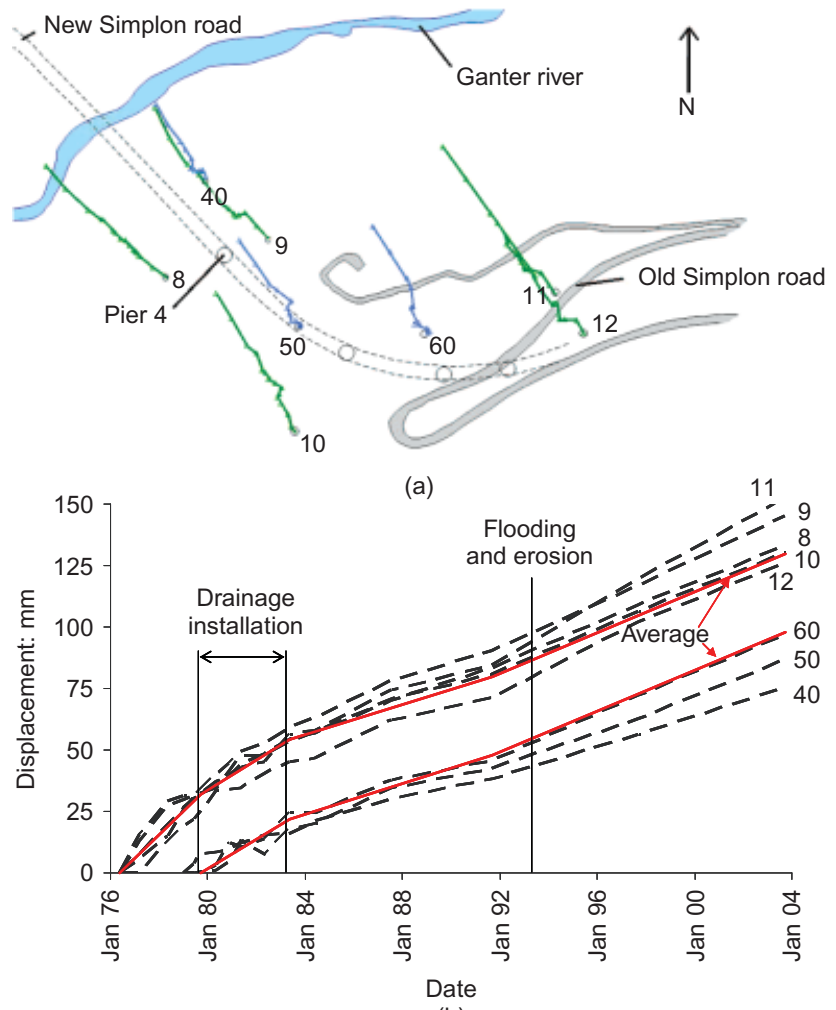

(b)

Fig. 9. Displacement measurements: (a) plan of measurement points with displacement vectors; (b) displacements in time from 1979 onwards additional points (40,50 and 60) were added to the measurements.

As can be seen in Fig. 9(b), in 1975-1979, before construction of the drainage, all points of the slide moved down at a similar rate, with an average constant velocity of $\dot{\delta}=9.6 \mathrm{~mm} /$ year. During construction of the drainage, in 1979-1982, the velocity dropped to $\dot{\delta}=6.0 \mathrm{~mm} /$ year, and after the end of the drainage installation it stabilised at an average of $\dot{\delta}=3.1 \mathrm{~mm} /$ year, with practically the same value for all the points on the slide. This demonstrates the efficiency of the drainage system, which managed to lower the groundwater table by $7 \mathrm{~m}$ : from $19 \mathrm{~m}$ below the ground surface to $26 \mathrm{~m}$ below the ground surface. In the year 1993 , however, as a result of severe flooding in this region, the bed of the Ganter river was eroded by about $1 \mathrm{~m}$, and the landslide displacement rates increased to an average of $\dot{\delta}=4.2 \mathrm{~mm} /$ year, remaining relatively constant, in both time and in space, in the 10 years following the flooding.

In addition to the geodetic measurements, an extensive geotechnical study was performed, including geoelectrical and seismic measurements. The soil properties were defined in laboratory and field test: the effective peak strength parameter $\phi_{\text {peak }}^{\prime}=37 \pm 1^{\circ}$, using back-calculation from plate bearing tests and from grain-size distribution after Dhawan (Lang \& Schaerer, 1974), additionally validated against peak values from ring shear tests; the residual angle of internal friction $\phi_{\text {res }}^{\prime}=23 \pm 2^{\circ}$ from ring shear tests; and the total unit weight $\gamma=22 \mathrm{kN} / \mathrm{m}^{3}$.

To separate the foundations of the bridge from the landslide, the initial idea was to found the bridge below the slip surface in the stable rock, with the piers of the bridge constructed inside vertical caisson shafts. But, because they have not reached the stable zone, these shafts have been moving with the sliding layer, gradually approaching the piers, which were designed to allow for corrections to their position to avoid contact between the caisson and the pier. To measure the earth pressure acting on the shaft, Glötzl pressure cells were installed at several depths at the contact of the caisson of pier 4 with soil. After completion of the construction these measurements did not show any pressure increase in the sliding layer.

\section{Analysis}

As can be seen in Fig. 9(b), in 1975-1979, before construction of the drainage, all points of the slide moved down at a constant velocity, $\delta=9.6 \mathrm{~mm} /$ year, in spite of the constraint at the bottom, indicating that: (a) the earth pressure at the bottom had reached the passive pressure; and (b) the slide had reached a steady state described by equation (44). After construction of the drainage was completed in 1982, the velocity decreased to $\delta=3.1 \mathrm{~mm} /$ year, and remained constant and similar for all the points on the slide, until 1993, when as a result of about $1 \mathrm{~m}$ erosion in the passive zone at the bottom the landslide uniformly accelerated to $\dot{\delta}=4.2 \mathrm{~mm} /$ year. The earth pressure in the landslide body at pier 4 , measured in 1979-1987 using Glötzl pressure cells, remained constant over the measurement period. The earth pressure at the bottom of the landslide also stayed fairly constant, as confirmed in $2008-2010$ by measurements performed with the help of the novel inclinodeformometer (Schwager et al., 2010).

From the above observations it follows that the steady state reached by the landslide due to the passive failure at the bottom before the bridge construction has not been disturbed by the drainage system construction and subsequent passive zone erosion. In other words, the landslide continues to move as a rigid body, as described by equation (44), with fluctuations in its velocity being caused by the changes in the corresponding parameters. This provides an 
opportunity for validation of the ability of equation (44) to predict landslide displacement rates.

Indeed, after calibrating the model for the pre-drainage phase, when the depth of the phreatic surface was $h_{\mathrm{w}}=19 \mathrm{~m}$ and the depth of the passive zone $h_{\mathrm{b}}=22 \mathrm{~m}$ (Lang \& Schaerer, 1980), its back-calculated parameter $\eta$ can be used for predicting the effects of the drainage (with the phreatic surface dropping deeper to $h_{\mathrm{w}}=26 \mathrm{~m}$ ) and subsequent erosion (with the depth of the passive zone decreasing to $\left.h_{\mathrm{b}}=21 \mathrm{~m}\right)$ on the landslide displacement rates. By comparing these estimated effects with the observed ones, the postfailure equation (44) can be validated.

First, using equation (44) and physical and geometric parameters from Table 2 , the viscosity coefficient $\eta$ can be estimated as

$$
\begin{aligned}
\eta & =\frac{1}{\dot{\delta}(x, \infty)}\left[\tau_{\mathrm{g}}-\tau_{\mathrm{r}}-\frac{h}{L}\left(p_{\mathrm{p}}-p_{\mathrm{a}}\right)\right] \\
& =1.35 \times 10^{11} \mathrm{kPa} \mathrm{s} / \mathrm{m}
\end{aligned}
$$

where evidence of the tension cracks in the sliding body allows the initial pressure to be assumed to be close to the active earth pressure, $p_{0}=p_{\mathrm{a}}$, so that the difference between earth pressures before the drainage was built is given by

$$
\begin{aligned}
p_{\mathrm{p}}-p_{\mathrm{a}}= & \frac{1}{2 h_{\mathrm{b}}}\left[\gamma h_{\mathrm{b}}^{2}-\gamma_{\mathrm{w}}\left(h_{\mathrm{b}}-h_{\mathrm{w}}\right)^{2}\right] K_{\mathrm{p}} \\
& -\frac{1}{2 h_{\mathrm{t}}}\left[\gamma h_{t}^{2}-\gamma_{\mathrm{w}}\left(h_{\mathrm{t}}-h_{\mathrm{w}}\right)^{2}\right] K_{\mathrm{a}} \\
= & 668 \mathrm{kPa}
\end{aligned}
$$

where $h_{\mathrm{b}}=h_{\mathrm{t}}=22 \mathrm{~m}$ are the average depths of the sliding surface at the bottom and top boundaries of the landslide respectively; and $K_{\mathrm{a}}$ and $K_{\mathrm{p}}$ are the active and passive earth pressure coefficients respectively (Puzrin \& Sterba, 2006, based on Chu, 1991), given by

$$
\begin{aligned}
\left\{\begin{array}{c}
K_{\mathrm{a}} \\
K_{\mathrm{p}}
\end{array}\right\}= & \cos \alpha\left[1+2 \tan ^{2} \phi_{\text {peak }}^{\prime}\right. \\
& \left.\mp 2 \sqrt{\left(1+\tan ^{2} \phi_{\text {peak }}^{\prime}\right)\left(\tan ^{2} \phi_{\text {peak }}^{\prime}-\tan ^{2} \alpha\right)}\right] \\
= & \left\{\begin{array}{l}
0.56 \\
3.34
\end{array}\right\}
\end{aligned}
$$

The gravitational shear stress and the residual shear strength before the drainage was built are given by

$$
\begin{aligned}
\tau_{\mathrm{g}} & =\gamma h \sin \alpha=376 \mathrm{kPa} \\
\tau_{\mathrm{r}} & =\left[\gamma h-\gamma_{\mathrm{w}}\left(h-h_{\mathrm{w}}\right)\right] \cos \alpha \tan \phi_{\mathrm{res}}^{\prime} \\
& =271 \mathrm{kPa}
\end{aligned}
$$

The back-calculated value of the viscosity (equation (51)) is two orders of magnitude higher than that obtained for the Combe Chopin landslide. Such variations between different landslides, as well as between the field- and laboratorydetermined values, are not uncommon (e.g. van Asch et al., 2007), and may be explained by the rate dependence of the viscosity, by the development of negative pore pressures on the sliding surface, and by the three-dimensional flow effects. The associated gain in strength results in a higher apparent viscosity. In the case of the Ganter slide, however, one of the major reasons for this difference is likely to be the stress dependence of the viscosity (Ter Stepanian, 1963), with the effective normal stresses acting on the sliding surface of the Ganter landslide being seven times higher than those in the Combe Chopin landslide.

After the drainage was built, the depth of the phreatic surface dropped to $h_{\mathrm{w}}=26 \mathrm{~m}$, and the new values of model parameters are calculated from

$$
\begin{aligned}
p_{\mathrm{p}}-p_{\mathrm{a}} & =\frac{1}{2} \gamma h_{\mathrm{b}} K_{\mathrm{p}}-\frac{1}{2} \gamma h_{\mathrm{t}} K_{\mathrm{a}} \\
& =673 \mathrm{kPa}
\end{aligned}
$$

and equations (54) to give

$$
\tau_{\mathrm{g}}=376 \mathrm{kPa} ; \tau_{\mathrm{r}}=297 \mathrm{kPa}
$$

\begin{tabular}{|c|c|c|}
\hline Parameter & Value & Derivation \\
\hline $\begin{array}{l}\text { Landslide length, } L: \mathrm{m} \\
\text { Average depth of sliding surface, } h: \mathrm{m} \\
\text { Average depth of sliding surface at bottom and top boundaries of landslide before erosion, } h_{\mathrm{b}} \text { and } h_{\mathrm{t}}: \mathrm{m} \\
\text { Average depth of sliding surface at bottom and top boundaries of landslide after erosion, } h_{\mathrm{b}} \text { and } h_{\mathrm{t}}: \mathrm{m} \\
\text { Average depth of phreatic surface before drainage construction, } h_{\mathrm{w}}: \mathrm{m} \\
\text { Average depth of phreatic surface after drainage construction, } h_{\mathrm{w}}: \mathrm{m} \\
\text { Average slope inclination, } \alpha: \text { degrees } \\
\text { Total unit weight of soil, } \gamma: \mathrm{kN} / \mathrm{m}^{3} \\
\text { Average peak angle of internal friction in sliding layer, } \phi_{\text {peak }}^{\prime}: \text { degrees } \\
\text { Average residual angle of internal friction on slip surface, } \phi_{\mathrm{res}}^{\prime}: \text { degrees } \\
\text { Gravitational shear stress, } \tau_{\mathrm{g}}: \mathrm{kPa} \\
\text { Residual shear strength, } \tau_{\mathrm{r}}: \mathrm{kPa}\end{array}$ & $\begin{array}{c}440 \\
42 \\
22 \\
21,22 \\
19 \\
26 \\
24 \\
22 \\
37 \\
23 \\
376 \\
271 \\
\\
297\end{array}$ & $\begin{array}{l}\text { Measured (field) } \\
\text { Measured (field) } \\
\text { Measured (field) } \\
\text { Measured (field) } \\
\text { Measured (field) } \\
\text { Measured (field) } \\
\text { Measured (field) } \\
\text { Measured (laboratory) } \\
\text { Measured (field) } \\
\text { Measured (laboratory) } \\
\text { Calculated } \\
\text { Calculated before drainage } \\
\text { construction } \\
\text { Calculated after drainage } \\
\text { construction }\end{array}$ \\
\hline
\end{tabular}

Then the back-calculated parameter (equation (51)) is substituted together with equations (55) and (56) into equation (44) to estimate the landslide velocity after the drainage was built in 1982, but before the flooding and erosion of 1993, as

$$
\begin{aligned}
\dot{\delta}(x, \infty) & =\frac{1}{\eta}\left[\tau_{\mathrm{g}}-\tau_{\mathrm{r}}-\frac{h}{L}\left(p_{\mathrm{p}}-p_{\mathrm{a}}\right)\right] \\
& =3.3 \mathrm{~mm} / \text { year }
\end{aligned}
$$

The observed value of the landslide velocity after drainage is $\dot{\delta}=3 \cdot 1 \mathrm{~mm} /$ year, indicating remarkable proximity between the predicted and observed values.

Finally, the effects of the erosion of the passive zone caused by the flooding of 1993 can be investigated by

Table 2. Summary of physical and geometrical parameters for Ganter landslide 
substituting $h_{\mathrm{b}}=21 \mathrm{~m}$ into equation (55), which gives $p_{\mathrm{p}}-p_{\mathrm{a}}=638 \mathrm{kPa}$, and after substitution together with the parameters from equations (51) and (56) into equation (44) allows the landslide velocity after the erosion to be estimated as

$$
\dot{\delta}(x, \infty)=\frac{1}{\eta}\left[\tau_{\mathrm{g}}-\tau_{\mathrm{r}}-\frac{h}{L}\left(p_{\mathrm{p}}-p_{\mathrm{a}}\right)\right]=4 \cdot 1 \mathrm{~mm} / \text { year }
$$

The observed value of the landslide velocity after erosion is $\dot{\delta}=4.2 \mathrm{~mm} /$ year, again indicating remarkable proximity agreement between the predicted and observed values.

\section{CONCLUSIONS}

The paper explores a simple analytical model in an attempt to quantify the evolution of a landslide stabilised by a retaining wall, or by a natural barrier at the bottom of the sliding mass. Within the model assumptions, the development in time of both the landslide displacements and the earth pressure acting on the retaining structure can be obtained in the closed form. Curiously, the solution for the pressure evolution is identical to the expression for the average degree of consolidation obtained by Terzaghi for the classical problem of one-dimensional consolidation. The model allows for a clear definition of the long-term safety factor for a stabilised landslide. Depending on the value of this safety factor, either the landslide will eventually slow down, asymptotically approaching final displacements given by the model, or the soil behind the retaining wall will experience passive failure at a certain moment in time, which can be predicted by the model. The model also provides an insight into the post-failure evolution of the landslide.

Two case studies based on monitoring data from the Combe Chopin and Ganter landslides in Switzerland were used to validate the model. For the Combe Chopin landslide, which has a long-term safety factor lager than unity, the model demonstrated its ability to predict final downhill displacements and their development in time. For the Ganter landslide, which had reached the passive pressure at the bottom, failed and achieved the steady-state velocity before displacement measurements commenced, the model correctly predicted the long-term landslide evolution and the effects of drainage and erosion on the displacement rates. In both cases the model allows for back-calculation of apparent shear viscosities for soil on the sliding surface, avoiding the high uncertainties associated with determination of the viscosity coefficients in laboratory tests.

While being promising in validating certain features of the model, these two case studies do not test the model's ability to predict the time of a landslide failure and the initial post-failure evolution of such a landslide. Additional case studies are therefore required, indicating a direction for future research.

\section{ACKNOWLEDGEMENTS}

The work has been partially supported by the ASTRA/ VSS grant VSS 2010/503 'Landslide-Road-Interaction: Applications'. The authors are grateful to A. Bisetti and B. Houriet (GVH Tramelan SA) for providing the data on the Combe Chopin landslide, and to the Department of Construction of Canton du Valais for providing the data on the Ganter landslide. The contribution of M. Schwager (ETH Zurich) to this study is highly appreciated.

\section{NOTATION}

$C$ constant in the differential equation $C=h E / \eta$

$c_{\text {peak }}^{\prime}$ peak cohesion in sliding layer

$E$ deformation modulus

$\operatorname{erf}(x)$ error function

FS safety factor

$G$ Green function

$h$ average depth of sliding surface

$h_{\mathrm{b}}, h_{\mathrm{t}}$ average depths of sliding surface at bottom and top boundaries of landslide

$h_{\mathrm{w}}$ average depth of phreatic surface

$K_{\mathrm{a}}, K_{\mathrm{p}}$ active and passive earth pressure coefficients

$k$ running variable in summation

$L$ landslide length

$n$ running variable in summation

$p(x, t)$ effective normal stress

$p_{\mathrm{a}}$ active earth pressure

$p_{\mathrm{p}}$ passive earth pressure

$p_{0}$ constant effective stress

$T$ integration variable in time

$T_{\mathrm{v}}$ time factor

$t$ time

$\bar{U}$ average degree of consolidation (Terzaghi, 1943)

$v$ landslide velocity

$\alpha$ average slope inclination

$\gamma$ total unit weight

$\gamma_{\mathrm{w}}$ unit weight of water

$\delta(x, t) \quad$ landslide displacement

$\dot{\delta}(x, t)$ landslide velocity

$\delta_{\mathrm{g}}(x, t)$ general solution of non-homogeneous equation

$\delta_{\mathrm{p}}(x, t)$ particular solution of homogeneous differential equation

$\varepsilon$ average strain in the sliding layer

$\eta$ viscosity coefficient

$\xi$ integration variable in space

$\tau^{*}$ total residual strength on the sliding surface

$\tau_{\mathrm{g}}$ gravitational shear stress

$\tau_{\mathrm{r}}$ rate-independent component of the residual shear strength

$\phi_{\text {peak }}^{\prime}$ peak angle of internal friction in sliding layer

$\phi_{\text {res }}^{\prime}$ average residual angle of internal friction on slip surface

\section{REFERENCES}

Bapst, A. (2002). N16: Traversée de la Combe Chopin conditions géologiques. Autumn Meeting of the Société Suisse de Mécanique des Sols et des Roches, Olten, pp. 59-72.

Bernander, S. \& Olofsson, I. (1981). On formation of progressive failures in slopes. Proc. 10th Int. Conf. Soil Mech. Found. Engng, Stockholm 3, 357-362.

Bisetti, A. (2002). Confortation et assainissement de la Combe Chopin analyse de stabilité. Autumn Meeting of the Société Suisse de Mécanique des Sols et des Roches, Olten, pp. $73-82$.

Bjerrum, L. (1967). Progressive failure in slopes of overconsolidated plastic clay and clay shells. J. Soil Mech. Found. Engng Div. ASCE 93, 1-49.

Chu, S. (1991). Rankine analysis of active and passive pressures in dry sands. Soils Found. 31, No. 4, 115-120.

Glastonbury, J. \& Fell, R. (2008). Geotechnical characteristics of large slow, very slow and extremely slow landslides. Can. Geotech. J. 45, No. 7, 984-1005.

Lang, H. J. \& Schaerer, Ch. (1973). N9: route de Simplon, traversée de la vallée de la Ganter, rapport 2774/2. Zurich: EPFZ Zurich, Institut de Technique des Fondations et de Mécanique des Sols, 24 January.

Lang, H. J. \& Schaerer, Ch. (1974). Simplonstrasse N 9, Gnaterüberquerung, rapport 2774/6. Zürich: ETH Zürich, Institut für Grundbau und Bodenmechanik, 10 October.

Lang, H. J. \& Schaerer, Ch. (1980). N9: route du Simplon, rapport relatif aux mesures et observations, rapport 2774/10. Zurich: EPFZ Zurich, Institut de Technique des Fondations et de Mécanique de Sols, 31 October.

Puzrin, A. M. \& Schmid, A. (2007). Utilization of TRIVEC measurements in the inverse analysis of the long-term stability of a constrained landslide. Proc. 7th Int. Symp. on Field Measurements in Geomechanics, Boston, MA (CD-ROM). 
Puzrin, A. M. \& Schmid, A. (2011). Progressive failure of a constrained creeping landslide. Proc. R. Soc. London A 467, 2444-2461.

Puzrin, A. M. \& Sterba, I. (2006). Inverse long-term stability analysis of a constrained landslide. Géotechnique 56, No. 7, 483-489, http://dx.doi.org/10.1680/geot.2006.56.7.483.

Schaerer, Ch. (1975). Ueberquerung des Ganterbaches. Mitt. Schweiz. Ges. Boden- und Felsmechanik, Spring, 1-4.

Schulz, W. H., Kean, J. W. \& Wang, G. (2009). Landslide movement in southwest Colorado triggered by atmospheric tides. Nature Geosci. 2, 863-866.

Schwager, M. V., Schmid, A. M. \& Puzrin, A. M. (2010). Inclinodeformometer for earth pressure measurements in creeping landslides. Soils Found. 50, No. 4, 451-458.

Skempton, A. W. (1964). Long-term stability of clay slopes. Géotechnique 14, No. 2, 77-102, http://dx.doi.org/10.1680/geot. 1964.14.2.77.

Skempton, A. W. \& La Rochelle, P. (1965). The Bradwell slip: a short-term failure in London clay. Géotechnique 15, No. 3, 221-242, http://dx.doi.org/10.1680/geot.1965.15.3.221.
Ter Stepanian, G. (1963). On the long-term stability of slopes. Norw. Geotech. Inst. 52, 1-14.

Terzaghi, K. (1936). Stability of slopes of natural clay. Proc. 1st Int. Conf. Soil Mech. Found. Engng, Cambridge, MA 1, 161165.

Terzaghi, K. (1943). Theoretical soil mechanics. New York: John Wiley \& Sons.

Terzaghi, K. (1950). Mechanism of landslides. In Application of geology to engineering practice (ed. S. Paige), pp. 83-123. New York: Geological Society of America.

van Asch, Th. W. J., Van Beek, L. P. H. \& Bogaard, T. A. (2007). Problems in predicting the mobility of slow-moving landslides. Engng Geol. 91, No. 1, 46-55.

Viamichelin (2007). http://www.viamichelin.de/viamichelin/deu/dyn/ controller/Karten

Viamichelin (2011). http://www.viamichelin.de/viamichelin/deu/dyn/ controller/Karten

Wiberg, N.-E., Koponen, M. \& Runesson, K. (1990). Finite element analysis of progressive failure in long slopes. Int. J. Numer. Anal. Methods Geomech. 14, No. 9, 599-612. 